\title{
Plants are More Effective in Absorbing Volatile Organic Compounds from the Atmosphere Than Air Purifiers
}

\author{
Aryaman Sokhal ${ }^{1}$ and Uttamesh Narayan ${ }^{1}$
}

${ }^{1}$ DPS International, Saket, New Delhi, India

\begin{abstract}
Volatile Organic Compounds (VOCs) have proved hazardous to human health, especially Benzene and Formaldehyde. The research focussed on comparing the effectiveness of plants and air purifiers in absorbing VOCs from the atmosphere. The latter solution contains HEPA filters and activated carbon filters, both of which are known to absorb VOCs. Two variables were tested, which included the level of Formaldehyde (HCHO) and the level of Total Volatile Organic Compounds (TVOC). The test was carried out by spraying equal amounts of deodorant in each room, one with the plant and one with the air purifier, to increase the amount of VOCs in the rooms to check how much was absorbed by the two levels of solutions. A pollution monitor was used to measure VOC concentrations. After carrying out statistical analysis (paired sample t-tests) at the $95 \%$ confidence level on software called JASP, it was shown that the plant used, Sansevieria Trifasciata, absorbed VOCs, especially Formaldehyde, more effectively than the air purifier.
\end{abstract}

\section{Introduction}

Volatile Organic Compounds, or VOCs, have become a primary cause of cancer, asthma, nausea, and migraines. This troubling development in recent years can be attributed to the chemical industry and their desire to keep expanding into different industries including Petroleum, perfumes, and the everyday cosmetics used by people. While numerous attempts have been made at coming up with ways to reduce the amount of PM 2.5 and other pollutants in the atmosphere, not much has been done to bring down the levels of VOCs that present a potent threat to human life. The researcher's passion for Green Chemistry and the positive impact it has is capable of leading him to do something for society, especially for the people who work in factories, petrol stations, and perfumeries, without knowing the long term implications of the VOC's they are exposed to daily. It is this aforementioned commitment to educate people regarding the ill effects of VOCs and contribute to the research that may improve the lives of those exposed to VOCs daily that forms the core reason for my interest in this project.

Another aspect of the rationale for this research question stems from the researcher's struggle with asthma that made him realize the ill effects of VOCs and the urgent need for a viable solution to address this health hazard. As the condition kept on deteriorating, to such an extent that in the past three years he had been rushed to the hospital twice, in the middle of the night because of being unable to breathe. As his condition kept deteriorating, he was forced to stay inside the house for days when there was a lot of pollen, dust, and pollution outside. Exposure to petrol pumps and perfumeries would trigger breathing problems that became a major deterrent to healthy functioning. Thus, the researcher formulating this question has an experiential understanding as to how dramatically breathing can change just because of these compounds. The discomfort experienced by our research partner made us wonder about the devastating consequences of working in places like a petrol pump. Their oblivion towards their mortality further reinforces the need for research of this kind. Therefore, the need to come up with a plausible solution to this expo- 
nentially growing problem was imperative. The constant wheezing and the effort made to take every breath is something many people go through regularly, living in one of the most polluted cities in the world, and thus I want to give back to society by coming up with a solution that can save many lives.

Thus, this research looked to compare air purifiers and plants to see if plants are as effective, or even more effective than air purifiers in reducing the levels of VOCs in a given area. A passion for sustainable solutions coupled with the growing need to find natural alternatives to chemical solutions led to the examination of plants as an effective VOC absorbing mechanism. The findings from this project will have a direct impact on workers in petrol stations and perfumeries since they are exposed to high levels of VOCs and research examining ways to mitigate the ill effects of VOCs will have a tangible impact. Moreover, this research will contribute to informing the healthcare sector with knowledge about the lowering of pollutants in the atmosphere. Furthermore, this research could also fulfill the goal of eliminating, or at least reducing, threatening levels of VOCs in the atmosphere by just absorbing them from where they are being emitted the most.

Thus far, researchers have either studied the effectiveness of VOC removal by activated carbon filters, which are present in air purifiers, or they have studied the effectiveness of VOC removal by plants. However, there hasn't been any comparative study which shows which, among the two is better in absorbing VOCs from the atmosphere. The gap mentioned in the literature review further reinforces the importance of conducting a comparative analysis to understand which solution is best for which environmental context.

\section{Literature Review}

In this section, the previous research that informed the core hypothesis, "Plants are better than air purifiers in absorbing Volatile Organic Compounds" is discussed. Thus, this section shall be divided into three sub-sections:

1) The harmfulness of Volatile Organic Compounds (VOCs)

2) The efficacy of plants in absorbing Volatile Organic Compounds

3) The efficacy of air purifiers in absorbing Volatile Organic Compounds

\section{The harmfulness of Volatile Organic Compounds (VOCs):}

Levels of Volatile Organic Compounds in the atmosphere are rising at an alarming rate in today's time. There has been a lot of concern about PM 2.5. However, VOCs can be as harmful as other pollutants adversely affecting the environment. Thus, a lot of research is being done to find a solution that results in the lowering of VOC levels. Like PM 2.5, VOC emissions can result in breathing problems, allergies, and even cancer. So it is necessary to find the best solution to save peoples' lives.

Formaldehyde is a very common VOC which is present in almost all industries and has been studied by researchers because it is believed to be a carcinogen. This research is being conducted using deodorants because deodorants contain formaldehyde that is a harmful exemplar of VOCs. This is also found in petrol stations and is released from our carpets and furniture. A research project examining the probability of cancer due to exposure to formaldehyde found that cancer in the nasopharynx was attributed to formaldehyde exposure (Blair, Saracci, Stewart, 1990). The paper also talked about how direct contact of formaldehyde with upper respiratory sites reveals that cancer is highly probable in occurring at these sites. In addition to this, deaths caused by myeloid leukemia increased significantly as formaldehyde exposure increased (Hauptmann, Stewart, Lubin, 2003). Another research conducted on the extent to which nasal and nasopharyngeal cancer was caused due to formaldehyde exposure concluded that both types of cancer were associated with formaldehyde exposure, after studying the occupations of cancer patients (Roush, Walrath, Stayner, 1987). A study conducted on 'Occupational formaldehyde exposure and increased nasal cancer risk in man' gathered statistics, using $95 \%$ confidence limits, and concluded that people working in environments with 
high levels of Formaldehyde were at a risk of cancer (Olsen, Jensen, Hink, 1984). These findings show that exposure to formaldehyde has been a major health risk for many years, and prove the fact that cancer, especially nasal cancer, has become a major issue, especially for those working amidst formaldehyde exposure.

The research was also conducted on the levels of formaldehyde inside homes, and it was found that people complained about symptoms like "Eye irritation, burning eyes, runny nose, or sore headache, and cough", and it was concluded that levels of formaldehyde inside non-occupational environments might go beyond those in working environments (Woodbury, Kanarek, Hanrahan, 1981). Moreover, further studies have shown that children exposed to formaldehyde are at a greater risk of getting asthma. A study conducted in Australia gathered statistics from children's' bedrooms and the results showed that children with asthma had greater levels of formaldehyde in their rooms (Rumchev, Spickett, Bulsara, 2001). A similar study was done, also in Australia, which didn't only test the homes of children with asthma, but tested whether formaldehyde exposure triggered common allergies, and the results they obtained had proved this (Garrett, Hooper, Rayment, 1998). However, the limitations of these two studies were that the effect of VOCs on adults, in terms of allergies and respiratory problems, was not taken into account. Significant data from the adult population would have yielded better results as the risks of formaldehyde exposure would have been spread across all ages. In conclusion, homes, especially the ones with children, should adopt solutions to protect the children from exposure to formaldehyde.

Furthermore, benzene is another common VOC that is said to affect health adversely. A study was conducted on Chinese workers working in different industries like the painting, and printing industries. The results showed that cases of leukemia, lung cancer, malignant lymphoma, and many other diseases, were more common in workers who were exposed to benzene in their place of work (Lin, Hayes, Linet, 1996). Another study conducted in China further emphasized this point as it concluded that benzene is most likely to cause cancer, compared to other VOCs (Li, Wang, Zhang, 2013). This was reiterated in many research papers. For example, a study conducted in Illinois concluded that "Lymphohematopoietic cancer mortality" was greater in workers exposed to high levels of benzene in their workplaces (Collins, Ireland, Buckley, 2003). Moreover, research shows that the most amount of benzene in the atmosphere comes from vehicles and power station emissions (Wallace, 1989). Adding to this, research conducted in Copenhagen agreed with the fact that traffic causes a lot of benzene emissions, and wind speed carries the benzene in the air to various places, as a result of which more places come under threat (Skov, Hansen, Lorenzen, 2000). So the solution to reduce VOC levels should be focussed on streets to protect pedestrians from toxic levels of the VOC, and it should be made sure that power station chimneys are fitted with VOC absorbing mechanisms.

In Hong Kong, research was conducted on the effect of VOCs in indoor environments and it showed that out of the environments studied (homes, offices, food services, etc.), kitchen areas had the highest exposure to volatile organic compounds. "Benzene accounted for about or more than $40 \%$ of the lifetime cancer risks for each category of the indoor environment", and "Higher lifetime cancer risks related to chloroform exposures were observed at the restaurant and the canteen", the research paper said (Guo, Lee, Chan, 2004). However, what the research lacked was that it did not study the concentrations of VOCs in places where they are emitted the most, such as perfumeries, petrol stations, and paint factories. For all these reasons, this research looks for plausible ways of reducing the levels of VOCs in the environment so that the risk is mitigated in both indoor and outdoor areas.

\section{The efficacy of plants in absorbing volatile organic compounds:}

The next section shall examine research that looked at how effective plants have been in absorbing VOCs. Studies have been done on many plants that can absorb Volatile Organic Compounds in both indoor and outdoor environments. The plant chosen for this research is 'Sansevieria trifasciata', commonly known as 'Snake Plant' or 'Mother in Law's Tongue'. This is because many studies have shown that it is quite effective in absorbing harmful VOCs like Formaldehyde and Benzene. A study conducted on thirty different plant species, to check which of them were effective in absorbing air pollutants like VOCs, concluded that Sansevieria trifasciata was one of the most effective ones in absorbing formaldehyde and benzene (Zhou, Qin, Su, 2011). Research has also shown that it is one of the few plants 
that release Oxygen at night too, hence enriching the air with pure oxygen (Srivatsan, 2015). Other studies conducted on comparing plants in terms of VOC absorption also show that Sansevieria trifasciata is effective in absorbing VOCs from the atmosphere. For example, a study conducted on VOCs like toluene and ethylbenzene showed that Sansevieria Trifasciata was the most effective in absorbing toluene among the group of plants, and was also quite effective in absorbing ethylbenzene (Sriprapat, Suksabye, Areephak, 2014). Overall, past research seems to indicate that plants can absorb, and therefore lower, the levels of VOCs in the atmosphere. A research that was conducted in both offices and homes concluded that many pot plants effectively cleaned the air in both environments (Tarran, Torpy, Burchett, 2007).

However, the research was limited to very few plant species, so it could not provide a lot of comparative data, unlike the study conducted on thirty different plant species. Another research done on eighty-six species of plants showed that many of the plants effectively absorbed formaldehyde from the surrounding air ((Kim, Jeong, Lee, 2010). In addition to this, a study was conducted to test the ability of plants to absorb formaldehyde from the air in different growing media and the results showed that in each growing medium, the plants were able to absorb formaldehyde effectively (Aydogan, Montoya, 2011). Many research papers reiterated the point that plants reduced levels of formaldehyde and benzene greatly. The research was done in which the control group was a room without plants and the experimental group was a room with plants. It was observed that the VOC concentration in the room with plants was greatly reduced (Song, Kim, Sohn, 2007). Research has also been done to see how effective plants are in absorbing benzene from the air. A study was done on seventy-six plant species, and it was observed that out of them, ten were very effective in absorbing benzene (Liu, Mu, Zhu, 2007).

Not a lot of research has been done on the efficacy of plants in absorbing VOCs from outdoor environments. Studies have also shown that even though plants absorb VOCs from the air, they release VOCs too. A study conducted in Honk Kong concluded that among the two plants studied, the level of formaldehyde absorbed by Sansevieria trifasciata was greater. The results showed that even though Aloe Vera was more efficient in absorbing formaldehyde initially, it wilted after a few days, and started emanating formaldehyde while Sansevieria trifasciata kept absorbing formaldehyde (Yin-hung, Kin-chung, Jing-liang, 2011). However, the paper also concluded that the two plants released different VOCs while absorbing formaldehyde. This led me to read another research paper which cited that among other plants, Sansevieria trifasciata emitted the least amount of volatile organic compounds and that many of the volatile organic compounds emitted are beneficial as they are anti-inflammatory and antioxidants (Yang, Son, Kays, 2009).

\section{The efficacy of air purifiers in lowering levels of Volatile Organic Compounds:}

While plants reduce VOC levels by absorption, air purifiers reduce VOC levels by adsorption. Air purifiers have an activated carbon filter which traps pollutant molecules on its surface. It is known to adsorb VOCs more effectively compared to other pollutants. Research has shown that activated carbon adsorbs VOCs from the air linearly as time progresses (VanOsdell, Owen, Sparks, 1996). Activated carbon filters are of many types. Research has been done to test whether activated carbon fiber adsorbs VOCs more effectively than granular activated carbon and the results reaffirmed our hypothesis (Das, Gaur, Verma, 2004). Research has also shown that activated carbon can be used to adsorb VOCs onto its surface, and then the VOCs can be recovered from it which makes it an economical process as the VOCs can be used for different purposes (Ruhl, 1993). Activated carbon filters have also been used in cars and have effectively reduced the levels of VOCs emitted from the cars (Moon, Kim, Kang, 2014). Studies have been carried out to test how efficient activated carbon is in adsorbing formaldehyde from the air. In some of these studies, the test was carried out on different types of activated carbon filters, and the results showed that formaldehyde was effectively being adsorbed from the air in the activated carbon filter containing hexamethylene diamine (Ma, Li, Zhu, 2011). Similarly, another study introduced amino groups into the activated carbon filters, and the results showed that after the amino groups were introduced, formaldehyde was being adsorbed more effectively (Tanada, Kawasaki, Nakamura, 1999). Investigations have been carried out on the effectiveness of activated carbon in adsorbing benzene. 
The results have shown that at appropriate surface areas, the activated carbon successfully lowered the levels of benzene (Huang, Kang, Liang, 2003). A similar study was conducted on how surface pores affect benzene adsorption and the results showed that low oxygen content and higher hydroxide content activated carbon adsorbed benzene most effectively (Lillo-Ródenas, Cazorla-Amorós, Linares-Solano, 2004). In most air purifiers, the activated carbon has titanium dioxide immobilized on it to adsorb VOCs more effectively because titanium dioxide acts as a catalyst in this process. Research has shown that titanium dioxide on activated carbon filter lowers VOC levels more effectively than activated carbon and titanium dioxide alone. A study was conducted on toluene and the results proved that titanium dioxide on activated carbon filter effectively lowers the levels of toluene (Ao, Lee, 2003).

Apart from activated carbon, air cleaners also contain another filter, the HEPA filter, which absorbs PM 2.5 and VOCs as well. Research has shown that HEPA filters are effective in absorbing VOCs as the research carried out a test in children's bedrooms and the HEPA filter lowered the VOC concentration (Xu, Raja, Ferro, 2008). A study was conducted on how effective each filter is in lowering levels of formaldehyde. The results showed that all filters were effective to some extent, but none of them was able to lower formaldehyde levels to match "WHO guidelines" (Tseng, Hsieh, Chen, 2005). For this reason, this paper draws a comparison between the absorption abilities of plants and air purifiers to see whether plants are better at reducing levels of formaldehyde or not. A study conducted on an activated carbon filter placed between a HEPA filter and a pre-filter inside an air purifier showed evidence that VOC levels were being lowered (Gallego, Roca, Perales, 2013).

Thus, previous research has effectively captured the veracity of the problem associated with VOCs in the air. Moreover, exposure to VOCs has proven implications for health issues that must be addressed. Thus, examining the efficacy of various solutions to mitigate the effects of VOCs is the need of the hour that this research hopes to contribute towards.

\section{Method}

\section{Materials}

To carry out this study, I used a Honeywell HAC25M1201W 53-Watt Room Air Purifier, which has HEPA filters and an Activated Carbon filter, for one room, and one pot of a fully grown Sansevieria Trifasciata plant for the other room. To measure the VOC levels, two SMILEDRIVE® Portable Air Quality Pollution Meters were used, which measure levels of PM 2.5, PM 10, Formaldehyde (HCHO), and Total Volatile Organic Compounds (TVOC). Two bottles of Axe Recharge Marine Splash deodorant were used throughout the research.

\section{Hypothesis and Research Design}

This study hypothesizes that plants are more effective in absorbing VOCs than air purifiers. To ensure a strong design for this research, numerous confounding variables needed to be accounted for. Thus, it was ensured that the rooms used for the experiment had the same dimensions (12ft x 16ft), and the same furniture (one bed, one bedside table, 2 cupboards, and 2 windows). The windows faced the same direction for both rooms. The windows were covered with curtains throughout the month when this research was being conducted. The rooms would be open throughout the day until the readings were taken. These were the variables that were controlled to ensure a level of generalizability to our findings. The independent variables of the study were the two solutions that were being tested- Level A: Plant, Level B: Air Purifier. The dependent variables were the amounts of $\mathrm{HCHO}$ and TVOC absorbed during the experiment.

\section{Hypothesis}

Plants are more effective in absorbing VOCs than air purifiers. 


\section{Procedure}

At 19:55 every day, a research associate and I would each take one bottle of deodorant and a VOC measuring meter respectively. The plant would be placed inside one room, after being picked up from the garden, and the door would be closed from inside, while the research associate would switch on the air purifier in the other room and close the door from inside. At 20:00, the meters would be switched on and would be kept on the bed, following which the deodorant would be sprayed four times in each room, once in each corner of the room. Once the levels of HCHO and TVOC increased to a maximum value and stabilized, the meters would be switched off, and we would leave the room, and close the door behind us. Then, at 22:00, we would enter our respective rooms with the meters again, close the doors, and switch the meters on. Once the HCHO and TVOC levels increased to a maximum value and stabilized, the readings were noted. Upon exiting our respective rooms, I would keep the plant in the garden again, while the associate would switch the air purifier off, and the doors were left open until the next day when we came back to take our readings. The readings were added to a spreadsheet. This due process was diligently followed for the duration of data collection, which was one month. The results from this research were tabulated on a spreadsheet following which the data analysis commenced on the JASP software.

\section{Results and discussion}

Table 1.1

\begin{tabular}{|l|l|l|l|}
\hline $\begin{array}{l}\text { Average absorption of } \\
\text { TVOC }\left(\text { Level A) } / \mathrm{mg} / \mathrm{m}^{3}\right.\end{array}$ & $\begin{array}{l}\text { Average absorption of } \\
\text { TVOC (Level B) } / \mathrm{mg} / \mathrm{m}^{3}\end{array}$ & $\begin{array}{l}\text { Average absorption of } \\
\text { HCHO (Level A) } / \mathrm{mg} / \mathrm{m}^{3}\end{array}$ & $\begin{array}{l}\text { Average absorp- } \\
\text { tion of HCHO } \\
\text { (Level B }) / \mathrm{mg} / \mathrm{m}^{3}\end{array}$ \\
\hline 8.821 & 8.728 & 1.151 & 1.093 \\
\hline
\end{tabular}

Table 1.1 shows the average absorption of TVOC and HCHO in both rooms.

The figures in the table support the proposed hypothesis of the research because the average values of absorption are greater for Level A than for Level B.

\section{Paired Samples T-Test}

Table 1.2

\begin{tabular}{|c|c|c|c|c|c|c|c|c|}
\hline & & & & & & & \multicolumn{2}{|c|}{$\begin{array}{c}95 \% \text { CI for } \\
\text { Mean Differ- } \\
\text { ence }\end{array}$} \\
\hline & & $t$ & df & $\mathbf{p}$ & Mean Difference & SE Difference & e Lower & Upper \\
\hline $\begin{array}{r}\text { Level A TVOC } \\
\text { absorbed } / \mathrm{mg} / \mathrm{m}^{3}\end{array}$ & $\begin{array}{c}\text { Level B TVOC ab- } \\
\text { sorbed } / \mathrm{mg} / \mathrm{m}^{3}\end{array}$ & 4.930 & 29 & $<.001$ & 0.093 & 0.019 & .061 & $\infty$ \\
\hline $\begin{array}{r}\text { Level A HCHO } \\
\text { absorbed } / \mathrm{mg} / \mathrm{m}^{3}\end{array}$ & $\begin{array}{c}\text { Level B HCHO ab- } \\
\text { sorbed } / \mathrm{mg} / \mathrm{m}^{3}\end{array}$ & 4.962 & 29 & $<.001$ & 0.059 & 0.012 & .039 & $\infty$ \\
\hline
\end{tabular}

Note. In all tests, the hypothesis is measurement one greater than measurement two. 
According to Table 1.2, the hypothesis that plants absorb VOCs more effectively than air purifiers holds. The results indicate that there is a statistically significant difference between the level of absorption of TVOC and HCHO at levels $\mathrm{A}$ and $\mathrm{B}(\mathrm{p}<0.001)$. This finding indicates that both plants and air purifiers are capable of working towards reducing pollutants in the air with plants performing that function better in the environmental conditions presented in our study.

Tables 1.3 and 1.5 in the Appendix show that the initial HCHO and TVOC levels were generally higher in the room with the plant than the room with the air purifier.

Tables 1.4 and 1.6 in the Appendix show that while the final TVOC level recorded for both rooms was generally the same, the final HCHO level in both rooms was significantly different.

Though this test was only conducted on VOCs, through the pollution meter one could observe that the PM 2.5 and PM 10 levels reached a minimum value in the room with the air purifier, while in the room in which the plant was present, the value remained the same after the two-hour test period.

\section{Discussion}

The results expected from this research were opposite to the results obtained. Since air purifiers are electrically operated, they can take in more air at a given instant of time compared to a plant. Therefore, it seemed that an air purifier would be able to absorb VOCs at a faster rate. However, this was proved to be wrong by the experiment as the plant absorbed more VOCs.

The fact that initial levels of VOCs were higher in the room with the plant supports previous research conducted on plants, especially Sansevieria Trifasciata, as it indicates that VOCs were emitted by the plant while the readings were being taken.

Furthermore, the fact that the final TVOC level was similar in both rooms generally means that the plant absorbed HCHO more effectively than it absorbed other VOCs present in the environment of the room.

The fact that PM 2.5 and PM 10 levels were lower in the room with the air purifier suggests that while plants absorb VOCs more effectively than air purifiers, air purifiers absorb PM 2.5 and PM 10 more effectively than plants. This implies that in environments where PM 2.5 and PM 10 are higher, air purifiers should be used and in environments where VOC levels are higher, plants should be used. For the best impact, both solutions should be used together.

The experiment was carried out in the absence of sunlight. It can therefore be predicted that a similar experiment conducted in an environment where sunlight is allowed to enter through the windows may increase the amount of VOCs absorbed by the plant as the rate of photosynthesis will be greater.

For the future scope of the research, researchers can study whether different plants behave similarly to Sansevieria Trifasciata, as more houseplants are known to absorb VOCs from the atmosphere. This may yield the most ideal solution to this escalating problem.

\section{Acknowledgments}

I would like to thank Mr. Prithvi Iyer for editing this paper and for providing all the support with understanding the format of the paper.

\section{Bibliography}

1.) Ao, C., \& Lee, S. (2005). Indoor air purification by photocatalyst $\mathrm{TiO} 2$ immobilized on an activated carbon filter installed in an air cleaner. Chemical Engineering Science, 60(1), 103-109. DOI: 10.1016/j.ces.2004.01.073

2.) Aydogan, A., \& Montoya, L. D. (2011). Formaldehyde removal by common indoor plant species and various growing media. Atmospheric Environment, 45(16), 2675-2682. DOI: 10.1016/j.atmosenv.2011.02.062 
3.) Blair, A., Saracci, R., Stewart, P. A., Hayes, R. B., \& Shy, C. (1990). Epidemiologic evidence on the relationship between formaldehyde exposure and cancer. Scandinavian Journal of Work, Environment \& Health, 16(6), 381-393. DOI: 10.5271/sjweh.1767

4.) Collins, J. J. (2003). Lymphohaematopoeitic cancer mortality among workers with benzene exposure. Occupational and Environmental Medicine, 60(9), 676-679. DOI: 10.1136/oem.60.9.676

5.) Daily, K. A., Hanrahan, L. P., Woodbury, M. A., \& Kanarek, M. S. (1981). Formaldehyde Exposure in Nonoccupational Environments. Archives of Environmental Health: An International Journal, 36(6), 277-284. DOI: 10.1080/00039896.1981.10667638

6.) Das, D., Gaur, V., \& Verma, N. (2004). Removal of volatile organic compound by activated carbon fiber. Carbon, 42(14), 2949-2962. doi: 10.1016/j.carbon.2004.07.008

7.) Gallego, E., Roca, F., Perales, J., \& Guardino, X. (2013). Experimental evaluation of VOC removal efficiency of a coconut shell activated carbon filter for indoor air quality enhancement. Building and Environment, 67, 1425. DOI: 10.1016/j.buildenv.2013.05.003

8.) Garrett, M., Hooper, M., Hooper, B., Rayment, P., \& Abramson, M. (1999). Increased risk of allergy in children due to formaldehyde exposure in homes. Allergy, 54(4), 330-337. DOI: 10.1034/j.1398-9995.1999.00763.x

9.) Guo, H., Lee, S., Chan, L., \& Li, W. (2004). Risk assessment of exposure to volatile organic compounds in different indoor environments. Environmental Research, 94(1), 57-66. DOI: 10.1016/s0013-9351(03)00035-5

10.) Hauptmann, M. (2003). Mortality From Lymphohematopoietic Malignancies Among Workers in Formaldehyde Industries. CancerSpectrum Knowledge Environment, 95(21), 1615-1623. DOI: 10.1093/jnci/djg083

11.) Huang, Z.-H., Kang, F., Liang, K.-M., \& Hao, J. (2003). Breakthrough of methyethylketone and benzene vapors in activated carbon fiber beds. Journal of Hazardous Materials, 98(1-3), 107-115. doi: 10.1016/s03043894(02)00284-4

12.) Kim, K. J., Jeong, M. I., Lee, D. W., Song, J. S., Kim, H. D., Yoo, E. H., .. Kim, H.-H. (2010). Variation in Formaldehyde Removal Efficiency among Indoor Plant Species. HortScience, 45(10), 1489-1495. DOI: 10.21273/hortsci.45.10.1489

13.) Li, L., Chen, Y., \& Xie, S. (2013). Spatio-temporal variation of biogenic volatile organic compounds emissions in China. Environmental Pollution, 182, 157-168. DOI: 10.1016/j.envpol.2013.06.042

14.) Lillo-Ródenas, M., Cazorla-Amorós, D., \& Linares-Solano, A. (2005). Behaviour of activated carbons with different pore size distributions and surface oxygen groups for benzene and toluene adsorption at low concentrations. Carbon, 43(8), 1758-1767. DOI: 10.1016/j.carbon.2005.02.023

15.) Liu, Y.-J., Mu, Y.-J., Zhu, Y.-G., Ding, H., \& Arens, N. C. (2007). Which ornamental plant species effectively remove benzene from indoor air? Atmospheric Environment, 41(3), 650-654. DOI: 10.1016/j.atmosenv.2006.08.001 
16.) Ma, C., Li, X., \& Zhu, T. (2011). Removal of low-concentration formaldehyde in air by adsorption on activated carbon modified by hexamethylene diamine. Carbon, 49(8), 2873-2875. doi: 10.1016/j.carbon.2011.02.058

17.) Moon, H. S., Kim, I. S., Kang, S. J., \& Ryu, S. K. (2014). Adsorption of volatile organic compounds using activated carbon fiber filter in the automobiles. Carbon Letters, 15(3), 203-209. doi: 10.5714/cl.2014.15.3.203

18.) Olsen, J. H., Jensen, S. P., Hink, M., Faurbo, K., Breum, N. O., \& Jensen, O. M. (1984). Occupational formaldehyde exposure and increased nasal cancer risk in man. International Journal of Cancer, 34(5), 639-644. doi: 10.1002/ijc. 2910340509

19.) Ruhl, M. J. (1993). Recover VOCs via adsorption on activated carbon. Retrieved from https://www.osti.gov/biblio/6124569-recover-vocs-via-adsorption-activated-carbon

20.) Rumchev, K., Spickett, J., Bulsara, M., Phillips, M., \& Stick, S. (2002). Domestic exposure to formaldehyde significantly increases the risk of asthma in young children. European Respiratory Journal, 20(2), 403-408. doi: 10.1183/09031936.02.00245002

21.) Skov, H., Hansen, A. B., Lorenzen, G., Andersen, H. V., Løfstrøm, P., \& Christensen, C. S. (2001). Benzene exposure and the effect of traffic pollution in Copenhagen, Denmark. Atmospheric Environment, 35(14), 24632471. doi: 10.1016/s1352-2310(00)00460-x

22.) Song, J.-E., Kim, Y.-S., \& Sohn, J.-Y. (2007). A study on improvement of indoor air quality by Korean native plants. Retrieved from https://www.isiaq.org/docs/papers/776.pdf

23.) Sriprapat, W., Suksabye, P., Areephak, S., Klantup, P., Waraha, A., Sawattan, A., \& Thiravetyan, P. (2014). Uptake of toluene and ethylbenzene by plants: Removal of volatile indoor air contaminants. Ecotoxicology and Environmental Safety, 102, 147-151. doi: 10.1016/j.ecoenv.2014.01.032

24.) Srivatsan, A. (2015). A Dual Sensor System for Determining the Unique Oxygen Production Signature of Plants Akshay Srivatsan - Semantic Scholar. Retrieved from https://www.semanticscholar.org/paper/A-Dual-SensorSystem-for-Determining-the-Unique-of/20e988cedc1b6849d93d71a00fd977abc7f96294

25.) Tanada, S., Kawasaki, N., Nakamura, T., Araki, M., \& Isomura, M. (1999). Removal of Formaldehyde by Activated Carbons Containing Amino Groups. Journal of Colloid and Interface Science, 214(1), 106-108. doi: 10.1006/jcis. 1999.6176

26.) Tarran, J., Torpy, F. R., \& Burchett, M. (2007). USE OF LIVING POT-PLANTS TO CLEANSE INDOOR AIR - RESEARCH REVIEW. Retrieved from https://greenplantsforgreenbuildings.org/wp-content/uploads/2014/01/PlantsCleanseIndoorAir.pdf

27.) Tseng, C.-H., Hsieh, C.-D., \& Chen, S.-S. (2005). The Removal of Indoor Formaldehyde by Various Air Cleaners. Retrieved from http://citeseerx.ist.psu.edu/viewdoc/download?doi=10.1.1.455.1382\&rep=rep1\&type=pdf 
28.) Vanosdell, D. W., Owen, M. K., Jaffe, L. B., \& Sparks, L. E. (1996). VOC Removal at Low Contaminant Concentrations Using Granular Activated Carbon. Journal of the Air \& Waste Management Association, 46(9), 883-890. doi: 10.1080/10473289.1996.10467524

29.) Wallace, L. A. (1989). Major Sources of Benzene Exposure. Environmental Health Perspectives, 82, 165. doi: $10.2307 / 3430770$

30.) Xu, Y., Raja, S., Ferro, A. R., Jaques, P. A., Surisetty, S., Qi, Y., ... Wetzel, L. E. (2008). Air cleaner effects on indoor air quality and asthmatic children's health. Retrieved from https://www.isiaq.org/docs/papers/844.pdf

31.) Yang, D. S., Son, K.-C., \& Kays, S. J. (2009). Volatile Organic Compounds Emanating from Indoor Ornamental Plants. HortScience, 44(2), 396-400. doi: 10.21273/hortsci.44.2.396

32.) Yin, S.-N., Hayes, R. B., Linet, M. S., Li, G.-L., Dosemeci, M., Travis, L. B., ... Group, T. B. S. (1996). An Expanded Cohort Study of Cancer among Benzene-Exposed Workers in China. Environmental Health Perspectives, 104, 1339. doi: 10.2307/3433187

33.) Yiu-hung, Y., Kin-chung, H., Jing-liang, X., Kwan-lung, L., \& Yu-hin, L. (2011). Evaluation of Two House Plants for Indoor Air Purification. Retrieved from http://en.cnki.com.cn/Article en/CJFDTotalCHCS201104001.htm

34.) Zhou, J., Qin, F., \& Jie Su, J.-wu L. (2011). Purification of formaldehyde-polluted air by indoor plants of Araceae, Agavaceae and Liliaceae. Retrieved from https://www.semanticscholar.org/paper/Purification-of-formaldehyde-polluted-air-by-indoor-Zhou-Qin/53d3c6f6eab41df5238d33e441b4e568eacaa06a 